\title{
Plan Twice, Measure Once: Designing a Financial Capability Service With Evaluation in Mind
}

\author{
Andrzej Walz-Chojnacki ${ }^{\text {a }}$ \\ ${ }^{1}$ Wisconsin Division of Vocational Rehabilitation \\ Keywords: vocational rehabilitation, training, financial capability \\ https://doi.org/10.52017/001c.27926
}

\section{Rehabilitation Counselors and Educators Journal}

Vol. 10, Issue 2, 2021

\begin{abstract}
An emphasis on career pathways in workforce development legislation and practice requires the public vocational rehabilitation (VR) program to explore an array of new services to those traditionally available to consumers. This manuscript examined the curriculum currently available for training providers to use in building consumers' financial capability, a key complement to career pathways, and describes a vision for a service that positively impacts consumers' financial well-being moving forward. Rather than analyzing the impact of services already in place, this manuscript aimed to elucidate the process of designing a service with intentionally-embedded outcome measures. This paper is intended to serve as a conceptual blueprint for VR evaluation professionals and foster the development of evidence supporting consumer access to financial empowerment tools and services that promote financial well-being and economic advancement.
\end{abstract}

\section{Background and Purpose}

The Rehabilitation Services Administration (RSA) is encouraging states to use career pathways to support individuals with disabilities in acquiring marketable skills and advancing opportunities for increased earnings and economic mobility. As Vocational Rehabilitation (VR) programs work to increase awareness and attention in promoting career pathways, it is important to also invest in building consumer financial capability, which includes financial literacy and the capacity to apply the information in one's life. The United States has low levels of financial literacy in general, particularly among people with lower educational attainment and income levels (Lusardi \& Mitchell, 2014). Individuals with lower income are less likely to have acquired access to fiancial institutions and services. For this reason, it is sensible to offer financial education and opportunity to those populations. As such, Wisconsin's strategic plan for 2016-2020 specifically noted, "the Division of Vocational Rehabilitation is currently focusing on programs that expand financial literacy...” (p. 51).

According to Sherraden (2013), people need both financial knowledge and financial inclusion to build financially secure and hopeful lives. To be financially capable, however, more than financial literacy is needed, as capability includes access to products and services that support individuals in acting in their best financial interest. McGarity and colleagues (2019) underscored the importance of aligning coaching with financial products as a means to increas- ing financial well-being. Using data from the National $\mathrm{Fi}$ nancial Capabilities Study, they suggested “...interventions that promote financial literacy may not be as effective as those that work to remove barriers and increase access to financial products" (p.12). Prior research examined existing school financial literacy programming and curricula, efforts by financial and other institutions, and state and federal policies targeting youth financial literacy (Mittapalli et al., 2009). Both shortcomings and opportunities were noted, as the majority of curricula were not designed for, did not allow for, or otherwise failed to consider learners with differing abilities. The authors suggested practical and realistic simulations be used to build skills, supporting the expectation of positive impact from skill building via coaching, which would surpass simulation with actual environments. They further concluded that a dearth of data regarding the efficacy of financial capability services for job seekers with disabilities, particularly youth, exists; “...research evidence on the effectiveness of these programs is few and far in between. Hence, it has been challenging to measure the overall impact of these programs” (p. 48).

Recent emphasis on career pathways and moving workforce development efforts for job seekers with disabilities beyond mere employment and toward economic self-sufficiency, is revealing a similar need for these job seekers to equip themselves with tools to ensure financial well-being along with increased wages. Emerging theories in the areas of financial capability, financial well-being, and financial empowerment suggest that financial literacy training 
alone may not be sufficient (Wagner, 2019). While discussion around these interrelated theories continues to evolve, more data is needed regarding the effectiveness and efficacy of varying approaches with individuals with disabilities.

The purpose of this study was twofold: (1) review the Wisconsin VR data in relation to financial literacy services, including service data and staff input, to inform development of a framework to guide future financial coaching services and evaluation in the Wisconsin VR program; and (2) identify currently existing financial literacy and financial coaching training models that can be used with VR consumers.

\section{Current Status}

Analysis of the Wisconsin case service data revealed that 168 (less than 1\%) of the total 21,970 consumers served by the state VR program received Financial Literacy services during Program Year 2019 (July 1, 2019, through June 30, 2020). Comparatively, 3,339 individuals (15\%) received related Work Incentive Benefits Analysis services. These findings suggested a need to further explore and expand financial empowerment service pathways for VR consumers in Wisconsin.

Financial Capability involves financial literacy training, but is further accompanied by coaching and access to financial products that support other behavioral strategies necessary for improving financial well-being. There is increasing interest in integrating Financial Capability services into VR to help improve longer-term economic outcomes for participants. This may be particularly important for those receiving Work Incentive Benefits Analysis services, as eligibility for public benefit programs is frequently aligned with a lack of economic resources. The initial assumption within DVR was that financial services would be referred to and provided in alignment with Work Incentive Benefits Analysis services. Therefore, it seemed plausible to assume the service would be delivered by the same community-based providers. DVR's conceptualization of the process was that Work Incentive Benefits Analysis services and Financial Capability services could be authorized individually, concurrently, or in succession, and would include consultation with guardians, representative payees, and care managers, among others. Activities within the service would verify budget elements, create a plan, and provide education on new services and emerging circumstances, consistent with financial coaching best practices as identified by Mittapalli et al. (2009). As such, the service was designed with three discrete service elements: (a) financial literacy education, (b) individualized assessment and plan, and (c) ongoing financial coaching. The services to do not need to be delivered in a specific order, nor are they all required, though they do form a natural progression.

Though the Financial Capability services design was informed by research, an intentional period of feedback provided an opportunity to gather perspectives from key stakeholders and account for operational realities. Input was actively gathered from (a) service providers currently delivering financial literacy programming; (b) employees of the state Division of Employment and Training; (c) Youth Tran- sition Services providers; (d) the full team of DVR Workforce Development Area Directors; and (e) individual conversations with directors and service providers currently delivering the services in their region. Stakeholder input was used to update service design, with references to "counseling" removed and replaced with "coaching," and the term "budget” replaced with "spending and savings plans.” Recommended outcome measures included (a) asset building, and (b) use of second and fourth quarter earnings after case closure.

\section{Comparison of Financial Literacy Curricula and Financial Coaching Training Options}

As a public program, Wisconsin DVR defines certain aspects of a service's parameters, while leaving flexibility for providers in meeting those requirements. As an example, DVR may prescribe the topics that need to be covered in a financial literacy training program, but not the actual curriculum to use. Likewise, DVR can require that financial coaching providers receive training or attain certification and provide an array of acceptable training and certification options, but not require they pursue one training over another. While it is incumbent upon the provider to demonstrate that the training selected meets VR's requirements, having an established list of training and credentialing options meeting these criteria is intended to promote higher quality service delivery and expedite processes, leading to improved outcomes. Existing Financial Literacy and Financial Coaching (a key element of Financial Capability) curricula were reviewed and compared to inform future service delivery requirements.

\section{Financial Literacy}

Financial literacy training is designed to increase consumer knowledge and understanding of various aspects involved with money management. While not all financial literacy training options were designed to meet the needs of the Wisconsin VR population, they nonetheless provided a reference for essential elements to include. Training content and trainer qualifications or requirements were two key issues to examine. Additionally, two Independent Living Centers adapted the Cents and Sensibility (Pennsylvania Assistive Technology Foundation, 2019) and Money Smart (Federal Deposit Insurance Corporation, 2021) curricula by including concrete examples and opportunities for handson practice, which were included in the review.

Based on the comparison data, Wisconsin DVR intends to specify that any curriculum used by providers must address the following topics (a) goal setting; (b) financial institution education; (c) the mechanics of making deposits and withdrawals; (d) budgeting, including the concepts of income and expenses; (e) borrowing and debt, including credit scores, risks, and different lending vehicles; and (f) safety, including identity theft. The curricula requirements noted in Mittapalli et al. (2009) were used to define the common content elements across four primary financial literacy training programs identified (see Table 1). 
Table 1. Comparison of Published Financial Literacy Curricula

\begin{tabular}{|c|c|c|}
\hline Institution & Title & Content topics \\
\hline Consumer Credit Counselling of Sheboygan & Financial Cent\$ & $\begin{array}{l}\text { SMART goals } \\
\text { Budget } \\
\text { Financial institution education } \\
\text { Protecting your money } \\
\text { Paycheck and taxes } \\
\text { Smart shopping tips } \\
\text { Warranties, guarantees, and extended warranties }\end{array}$ \\
\hline Pennsylvania Assistive Technology Foundation & Cents and Sensibility & $\begin{array}{l}\text { Money mapping } \\
\text { Personal money map } \\
\text { Saving } \\
\text { Financial institution education } \\
\text { Borrowing } \\
\text { Purchase of assistive technology } \\
\text { Plan development/resource identification }\end{array}$ \\
\hline Federal Deposit Insurance Company & Money Smart & $\begin{array}{l}\text { Money habits } \\
\text { Budgeting } \\
\text { Income } \\
\text { Expenses } \\
\text { Cost of living } \\
\text { Banking basics } \\
\text { Identity theft }\end{array}$ \\
\hline Consumer Financial Protection Bureau & Your Money, Your Goals & $\begin{array}{l}\text { Setting goals } \\
\text { Saving } \\
\text { Tracking income and benefits } \\
\text { Paying bills } \\
\text { Getting through the month } \\
\text { Dealing with debt } \\
\text { Understanding credit reports and scores } \\
\text { Choosing financial products and services } \\
\text { Protecting your money }\end{array}$ \\
\hline
\end{tabular}

\section{Financial Coaching}

To address the issue of financial coaching trainer qualifications and/or requirements, an existing inventory of financial coaching training curricula developed by Collins and Lienhardt (2014) was used. While 12 organizations were identified in the original inventory, those designed to train frontline staff, volunteer coaches, and instructors were prioritized. A thorough review of all training curricula was not feasible, as some organizations were no longer operating or their training curricula were not publicly available. The training curricula were available and reviewed for the remaining six, however. The inventory served as a guide to identify existing financial coaching training meeting the recommended requirements; see Table 2.

\section{Implementation and Evaluation}

During the course of this comparison, it became clear that organizations commonly used standards and core competencies established by others. For example, Prosperity Now names the standards cited by the University of Wisconsin, while Sage Financial Solutions uses those established by the AFCPE. As such, Wisconsin DVR opted to recommend that successful completion of any training endorsed by the University of Wisconsin-Madison Center for Financial Security would be acceptable. In practice, it is anticipated that many providers will avail themselves of the training offered by the University of Wisconsin Extension, due to its low cost and local availability.
The underlying tenet of these trainings, which parallel the VR philosophy, is an emphasis on individualization and "meeting the consumer where they are." Wisconsin VR expects person-centeredness will be second nature to current VR service providers, but needs to account for the fact that not all providers will necessarily be steeped in the tradition of serving job seekers with differing abilities. An emphasis on training financial concepts is preferable, but should also consider the training capacity preparation needs of a wide range of potential providers. Movement toward evidencebased approaches is key; however the need for flexible implementation is arguably equally important, as curriculum will likely require adaptation and modification to meet the needs of the diverse population served by DVR.

For ongoing evaluation, the efficacy of curricula would need to be assessed. The Financial Well-Being Scale, developed by the Consumer Financial Protection Bureau (2017), is an example of a psychometrically sound instrument to consider. This scale is brief (5- or 10-item versions available), valid and reliable, publicly available, and designed to consistently quantify one's financial capability (Consumer Financial Protection Bureau, 2017). Data from a well-designed and evaluated service can add valuable knowledge to the body of evidence regarding financial coaching and outcomes with individuals with disabilities. As noted by Lee and colleagues (2020), the instrument may also be helpful in measuring differences between receipt of financial literacy training and approaches that further integrate a coaching component. This may be instrumental in better 
Table 2. Financial Coaching Training Curricula Comparison*

\begin{tabular}{|c|c|c|c|}
\hline Organization & Mode & Target audience & $\begin{array}{l}\text { Coaching skills and } \\
\text { practice }\end{array}$ \\
\hline $\begin{array}{l}\text { Association for Financial Counseling and Planning Education } \\
\text { (AFCPE) }\end{array}$ & $\begin{array}{l}\text { In-person } \\
\text { Online }\end{array}$ & Frontline staff & Yes \\
\hline Baltimore CASH & In-person & Volunteer Coaches & Yes \\
\hline Cities for Financial Empowerment & In-person & $\begin{array}{l}\text { Frontline staff } \\
\text { Instructors or } \\
\text { trainers } \\
\text { Students }\end{array}$ & No \\
\hline $\begin{array}{l}\text { Center for Asset Building Opportunities (now known as } \\
\text { Prosperity Now) }\end{array}$ & In-person & Frontline staff & Yes \\
\hline Sage Financial Solutions & $\begin{array}{l}\text { In-person } \\
\text { Online }\end{array}$ & $\begin{array}{l}\text { Frontline staff } \\
\text { Instructors or } \\
\text { trainers } \\
\text { Volunteer coaches } \\
\text { Organization } \\
\text { leadership }\end{array}$ & Yes \\
\hline University of Wisconsin Cooperative Extension & In-person & $\begin{array}{l}\text { Frontline staff } \\
\text { Volunteer coaches }\end{array}$ & Yes \\
\hline
\end{tabular}

*Excerpt from the full table available in Collins \& Lienhardt, 2014

understanding whether existing financial literacy training programs need to be modified to successfully serve individuals with disabilities.

\section{Recommendations and Implications for Practice}

This paper serves to inform discussion and design of a pilot project focused on (a) effective integration of financial capability training into VR practice; and (b) measurement of financial well-being outcomes to determine whether the service resulted in positive change. Importantly, the longerterm aim of such a study is to inform development of an evidence-based financial capability service that measurably improves the lives of individuals with disabilities engaged with the public VR program. Demonstrating the efficacy of a financial capability model, inclusive of both financial literacy training and financial coaching, can help build evidence for expanding this service within the Wisconsin DVR program, and provide a blueprint for other states to replicate and expand upon. Based on findings from this study, the following recommendations are offered based on lessons learned:

- State VR programs are encouraged to review their data to better understand gaps in (a) consumer financial well-being and (b) financial capability services.

- Expanding consumer access to financial capability services that include both financial literacy training and coaching is an important consideration in improving financial well-being for individuals with disabilities.

- Design and implementation of a pilot, such as that proposed in this paper, can help move financial capability services for individuals with disabilities served through VR toward the evidence-based continuum.

- Integration of specific measures, such as asset building, post-VR case closure earnings, and financial wellbeing, should be considered early in the design process, reviewed throughout the pilot, and modified as needed before scaling-up the service.

- For VR programs such as Wisconsin that contract with vendors to provide services, it is recommended that authorizations for ongoing financial coaching specify details regarding the number of sessions or hours of service provision, hourly rate, and time period over which assistance will be provided.

- Monitor longer-term outcomes and impact following implementation of this service to better understand cost-benefits, impact, and improved quality of life for individuals served through the public VR program.

\section{Author Note}

The contents of this paper were developed under a cooperative agreement with the U.S. Department of Education, Technical Assistance Center for Vocational Rehabilitation Agency Program Evaluation and Quality Assurance (PEQA-TAC) (Grant Award Number: H263B150004). However, the contents and views expressed in this publication do not necessarily represent the positions or policies of the U.S. Department of Education, and you should not assume endorsement by the Federal government. 


\section{References}

Collins, J. M., \& Lienhardt, H. B. (2014). Financial coaching training curricula: Field inventory and summary brief. Center for Financial Empowerment, University of Wisconsin-Madison. https://fyi.extensio n.wisc.edu/financialcoaching/files/2014/08/CFS-Finan cial-Coaching-Curricula-Brief2.pdf

Consumer Financial Protection Bureau. (2017). Financial Well-Being Scale. https://www.consumerfinance.gov/d ata-research/research-reports/financial-well-being-sc ale/

Federal Deposit Insurance Corporation. (2021). Money smart: A financial education program. https://www.fdi c.gov/resources/consumers/money-smart/index.html

Lee, J. M., Lee, J., \& Kim, K. T. (2020). Consumer financial well-being: Knowledge is not enough. Journal of Family and Economic Issues, 41(2), 218-228. https://doi.org/10.1007/s10834-019-09649-9

Lusardi, A., \& Mitchell, O. S. (2014). The economic importance of financial literacy: Theory and evidence. Journal of Economic Literature, 52(1), 5-44. https://do i.org/10.1257/jel.52.1.5
McGarity, S., Okech, D., Risler, E., \& Clees, T. (2019). Assessing financial capability among people with disabilities. Journal of Social Work, 20(5), 657-672. htt ps://doi.org/10.1177/1468017319860308

Mittapalli, K., Belson, S., \& Ahmadi, H. (2009). Financial literacy for youth with disabilities. Social Dynamics. https://www.dol.gov/sites/dolgov/files/ode $\mathrm{p} /$ research/financialeducationyouthdisabilitiesliterat urereview.pdf

Pennsylvania Assistive Technology Foundation. (2019). Cents and sensibility: A guide to money management. ht tps://patf.us/what-we-do/financial-education/

Sherraden, M. (2013). Building blocks of financial capability. In J. Birkenmaier, M. Sherraden, \& J. Curley (Eds.), Financial education and capability: Research, education, policy, and practice (pp. 3-40). Oxford University Press.

Wagner, J. (2019). Financial education and financial literacy by income and education groups. Journal of Financial Counseling and Planning, 30(1), 132-141. htt ps://doi.org/10.1891/1052-3073.30.1.132 